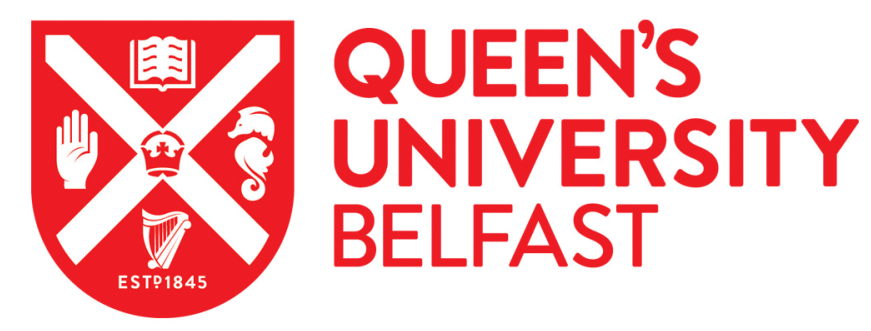

\title{
Mechanical behaviour of NiTiNb Shape Memory Alloy Wires- Strain Localisation and Effect of Strain Rate
}

Suhail, R., Chen, J. F., Amato, G., \& McCrum, D. (2020). Mechanical behaviour of NiTiNb Shape Memory Alloy Wires- Strain Localisation and Effect of Strain Rate. Mechanics of Materials, 144, [103346].

https://doi.org/10.1016/j.mechmat.2020.103346

\section{Published in:}

Mechanics of Materials

\section{Document Version:}

Peer reviewed version

\section{Queen's University Belfast - Research Portal:}

Link to publication record in Queen's University Belfast Research Portal

\section{Publisher rights}

Copyright 2020 Elsevier

This manuscript is distributed under a Creative Commons Attribution-NonCommercial-NoDerivs License

(https://creativecommons.org/licenses/by-nc-nd/4.0/), which permits distribution and reproduction for non-commercial purposes, provided the author and source are cited.

\section{General rights}

Copyright for the publications made accessible via the Queen's University Belfast Research Portal is retained by the author(s) and / or other copyright owners and it is a condition of accessing these publications that users recognise and abide by the legal requirements associated with these rights.

Take down policy

The Research Portal is Queen's institutional repository that provides access to Queen's research output. Every effort has been made to ensure that content in the Research Portal does not infringe any person's rights, or applicable UK laws. If you discover content in the Research Portal that you believe breaches copyright or violates any law, please contact openaccess@qub.ac.uk. 


\section{Mechanical behaviour of NiTiNb Shape Memory Alloy Wires- Strain 2 Localisation and Effect of Strain Rate}

\section{R. Suhail ${ }^{1, *}$, J.F. Chen ${ }^{1}$, G. Amato ${ }^{1}$ and D. McCrum $^{2}$}

${ }^{1}$ School of Natural and Built Environment, Queen's University Belfast, Belfast, BT9 5AG, UK

${ }^{2}$ University College Dublin, School of Civil Engineering, Newstead Building, Dublin 4, Ireland.

* Corresponding author: rsuhail01@qub.ac.uk

\section{Abstract}

12 Over the past few years, shape memory alloys (SMAs) have received increased attention in civil engineering research due to their unique features such as superelasticity, shape memory effect (SME), high ductility and good corrosion resistance. SMAs, however, have complex material behaviour which depends on many parameters such as chemical composition, thermo-mechanical treatment and ambient temperature. SMAs exhibit high strain-rate sensitivity and strong strain localisation during the stress-induced martensitic (SIM) phase transformation. Both have serious implication in civil engineering applications. Strain rate effects and the strain localisation in SMAs have been commonly investigated separately in the literature which has been mostly focused on NiTi SMA. This paper investigates the strain localisation phenomenon, the effect of strain rate and their interaction in NiTiNb SMA. The digital image correlation (DIC) technique was used to investigate the strain localisation phenomenon. The effect of strain rates is investigated within the quasi-static range and varies from $3.3 \times 10^{-5} / \mathrm{s}$ to $3.3 \times 10^{-2} / \mathrm{s}$ in strain-controlled tests and $2 \times 10^{-5} / \mathrm{s}$ to $2 \times 10^{-1} / \mathrm{s}$ in displacement-controlled tests. Significant non-uniform strain distribution is observed during the SIM phase transformation, which progresses through the nucleation and broadening of the transformation bands (TBs). The nucleation of the TBs and the unloading strain recovery within the TBs show high strain-rate sensitivity. At high strain rates, the nucleation of a TB is accompanied by a significant stress-drop.

Keywords: Shape memory alloys, SMA, stress-induced martensitic phase transformation, DIC, NiTi, NiTiNb, strain rate. 


\section{Introduction}

2 Shape memory alloys (SMAs) possess several unique features. The two prominent features are superelasticity (SE)

3 which is the ability of the material to recover large strain through removal of applied load, and the shape memory effect

4 (SME) which is the ability of the material to recover strain by heating. Both SE and SME are related to martensitic

5 transformation (MT), which is a diffusionless phase transformation often caused by reversible shear lattice distortion

6 [1,2]. When SMAs are deformed in their austenite phase, they undergo stress-induced martensitic (SIM) phase

7 transformation and give rise to multiple localized bands of martensites. In superelastic SMAs, stress-induced martensite

8 is transformed back to austenite when the stress is reduced on unloading, resulting in its superelastic behaviour. The

9 superelasticity in SMAs is highly sensitive to thermo-mechanical treatment. When SMAs are annealed above their

10 recrystallization temperature, as is the case in this study, they exhibit only partial superelasticty [3]. In fully annealed

11 austenitic SMAs, the oriented martensite formed during the SIM phase transformation is retained on unloading, just like

12 the martensitic SMAs, which result in large residual deformation (strain). The residual strain retained on unloading can

13 however be recovered by heating SMA above its austenite finish temperature, although in some SMAs only partial

14 recovery is achieved.

15 Among various types of SMAs developed to date, NiTi and NiTi-based SMAs are the most common type of SMAs

16 being used [4-6] due to the excellent combination of their properties including large strain recovery, high damping

17 capacity, good fatigue and corrosion resistance. The application domain of SMAs is increasingly widened by the

18 addition of new compositions. This study focuses on fully annealed NiTiNb SMA. The ternary addition of Niobium

$19(\mathrm{Nb})$ to Ni-Ti matrix significantly enhances the mechanical properties of the alloy by widening the thermal hysteresis

20 [7], and increasing the damping capacity and yield strength of the alloy [8]. NiTiNb SMA in annealed state has been

21 used by many researchers for active confinement and heat-activated prestressing of structural elements $[9,10]$. In an

22 annealed state NiTiNb SMA retains deformation (pre-strain) on unloading at room temperature. The retained strain is

23 recovered (generally only partially) on heating due to shape memory effect. Partial strain recovery in annealed NiTiNb

24 is generally not a problem in heat activated pre-stressing applications because on heating, a considerable amount of

25 recovery stress (prestress) is developed in the NiTiNb SMA if the retained pre-strain is restrained. The recovery stress

26 in the NiTiNb SMA can be very conveniently used in prestressing of structural elements without the need of traditional

27 mechanical tools and therefore opens a new gateway for heat-activated prestressing. 
Although many studies have been conducted either on material characterization of SMAs [11-13] or exploiting their

unique features for potential civil engineering applications (for e.g. [9, 14-16]. However, one important aspect of the material behaviour of SMAs that has generally been overlooked across these studies is the strain localisation. The nonhomogeneous nature of the phase transformation in SMAs is further exacerbated by the loading-rate sensitivity [17], which also has not received much attention when it comes to NiTiNb SMAs. Both phenomena have serious implication in engineering applications especially under dynamic loading such as earthquake, impact and blast which may produce high strain rates.

It is well known that SMAs have the propensity to form localised bands of large strain during the SIM phase transformation $[18,19]$. The mechanical behaviour of SMAs is governed by solid-solid phase transition process between different crystal structures [20]. The phase transition undergoes through discrete events of nucleation and growth of micro-domains at grain level and involves intrinsic material instability and dissipative evolution of the micro domains [19]. The phase transformation is accompanied by the localised release/absorption of latent heat. Therefore, thermomechanical coupling is inherent in the process and significantly influences the material behaviour both at micro- and macro-level [19,21-23]. Under the quasi-static tensile loading, the SIM phase transformation takes place through the manifestation of macroscopically observable domain(s) (transformation bands), the evolution of which is strongly coupled with heat transfer within the material and the surrounding environment. The transformation bands (TBs) appear at the start of the stress plateau in the stress-strain curve. The beginning and the end of the stress plateau in the stressstrain curve of SMAs are associated with initiation and complete propagation of the localised reorientation bands (TBs) [18]. Phase transformation, however, starts before the start of the stress plateau in the stress-strain curve and continues even after the end of the stress plateau [24,25]. Over the stress plateau region, the strain in the TBs is limited to characteristic transformation strain, which is generally indicated by the strain corresponding to the end of stress plateau, until the complete propagation of TBs take place in the SMA [26]. The characteristic transformation strain of an SMA depends on parameters such as grain size, composition of alloy, strain-rate and the thermo-mechanical treatment $[1,2,24]$.

Among many aspects of the material's behaviour concerned, the pattern and the rate dependency of the TBs formed during SIM phase transformation, stress hysteresis (of the macroscopic stress-strain curve), and the influence of associated temperature fields are of importance for structural applications of the material. Zhang et al. [19] showed that with the increase in the strain rate from $10^{-4} / \mathrm{s}$ to $10^{-1} / \mathrm{s}$, the number of TBs in NiTi SMA increases monotonically. The overall deformation tends to be more homogeneous due to increase in the number of TBs. The nominal stress-strain 
curves changes from plateau-type with distinct stress-drops at low strain rate to smooth and hardening type at high strain rates $[19,27]$. Despite insignificant stress plateau in the stress-strain curves at high strain rates, SIM phase transformation still takes place at higher strain [27,28]. Most of the existing studies on strain localisation and strain rate effects in SMAs have focused on superelastic NiTi SMAs. NiTiNb alloy, which is a preferred type of SMA for seismic engineering applications due to its wide hysteresis and has been widely used in civil engineering research (for example $[10,29,30]$ has not received much attention. Moreover, the combined effect of strain rate and strain localisation on the mechanical behaviour of NiTiNb SMAs has not yet been investigated to the best knowledge of the authors. In this study the strain localisation phenomenon, the effect of strain rate and their interaction in a fully annealed NiTiNb SMA is investigated for the first time. A comparison of loading method (displacement control vs strain control), and the effect of different strain measurement techniques on the stress-strain behaviour is also investigated in this study.

\section{Experimental procedures}

In this study, material characterization of the as-received SMA wire was conducted first to determine its chemical composition, phase and the transformation temperatures. The SMA wires used in this study were $2 \mathrm{~mm}$ in diameter and fully annealed at $850^{\circ} \mathrm{C}$ for $1.7 \mathrm{ks}$. The composition of the SMA was determined by the energy dispersive spectroscopy (EDS) using a FEI Quanta600 SEM, equipped with an energy dispersive X-ray analyser. Phase of the SMA was identified by the X-ray diffraction (XRD) analysis in PANalytical Xpert'pro diffractometer using CuK $\alpha$ radiation. The transformation temperatures were determined by the differential scanning calorimetry (DSC) using a Perkin Elmer diamond DSC.

Tensile tests, summary of which is given in Table 1, of SMA specimens were conducted to determine the mechanical properties. All tests were conducted at room temperature. Specimens taken from NiTiNb wire were tested under uniaxial monotonic and cyclic loading, and under uniaxial loading and unloading at different strain rates using a Zwick Roell universal testing machine equipped with $100 \mathrm{kN}$ load cell. The accuracy of the load cell as per the manufacturer's calibration chart was given as $\pm 0.02 \%$ over the range of $0-5 \mathrm{kN}$. Specimens were anchored in the testing machine using body over wedge grips. The length of the specimens between the grips was equal to $110 \mathrm{~mm}$ in Tests $1-7$ and $80 \mathrm{~mm}$ in Tests 8-14.

Strains in the specimens were measured using either a video-extensometer or the DIC technique, see Table 1. The reason for using two different measurement methods was that the video-extensometer set-up allowed the tests to be carried out 
1 under strain-control but could only measure the average strain within a pre-defined gauge length, while the DIC

2 technique allowed full-field strain measurements but tests could only be carried out under displacement-control. The

3 DIC technique has been used widely in civil engineering research (e.g. [31]).

Table 1. Summary of the tensile tests

\begin{tabular}{|c|c|c|c|c|}
\hline Test number & Test Type & Loading method & $\begin{array}{l}\text { Strain measurement } \\
\text { method }\end{array}$ & $\begin{array}{l}\text { Strain rate } \\
(1 / \mathrm{s})\end{array}$ \\
\hline Test 1 & \multirow{2}{*}{ Monotonic } & Strain control & Video-extensometer & $3.3 \times 10^{-3}$ \\
\hline Test 2 & & Displacement control & DIC & $1.5 \times 10^{-3}$ \\
\hline Test 3 & Cyclic & Displacement control & DIC & $1.5 \times 10^{-3}$ \\
\hline Test 4 & \multirow{11}{*}{$\begin{array}{l}\text { Strain rate tests } \\
\text { (loading and } \\
\text { unloading) }\end{array}$} & \multirow{4}{*}{ Strain control } & \multirow{4}{*}{ Video-extensometer } & $3.3 \times 10^{-5}$ \\
\hline Test 5 & & & & $3.3 \times 10^{-4}$ \\
\hline Test 6 & & & & $3.3 \times 10^{-3}$ \\
\hline Test 7 & & & & $3.3 \times 10^{-2}$ \\
\hline Test 8 & & \multirow{7}{*}{ Displacement control } & \multirow{7}{*}{ DIC } & $2.0 \times 10^{-5}$ \\
\hline Test 9 & & & & $2.0 \times 10^{-4}$ \\
\hline Test 10 & & & & $2.0 \times 10^{-3}$ \\
\hline Test 11 & & & & $2.0 \times 10^{-2}$ \\
\hline Test 12 & & & & $5.2 \times 10^{-2}$ \\
\hline Test 13 & & & & $1.0 \times 10^{-1}$ \\
\hline Test 14 & & & & $2.0 \times 10^{-1}$ \\
\hline
\end{tabular}

6 A Zwick Roell high precision non-contact single camera video extensometer was used to measure strains in Test 1 and

7 Tests 4-7 (refer to Table 1). The accuracy of the video extensometer depends on the field of view (FOV), which is the 8 extent of the observable world that is viewed through a video-extensometer camera. The FOV depends on the distance 9 between the camera and the specimen, and the focal length of the lenses. In this study, the FOV was set between 100-

$10200 \mathrm{~mm}$ which gives a minimum accuracy of $1 \mu \mathrm{m}$ according to the user manual. The maximum frame rate/ data

11 acquisition-rate of the video-extensometer is given as $500 \mathrm{fps}$ in the user manual. Before the start of each test, the

12 video extensometer was calibrated using a scale provided by the manufacturer. Calibration for geometrical lens 13 distortion was carried out using a black and white checkerboard.

14 To measure strains using the video-extensometer, two lighting methods are used: the front-light method in which the 15 video-extensometer and the light are directed in the same direction, towards the specimen; and the back-light method in 16 which the lighting device and the video-extensometer are directed in opposite direction with the specimen placed in 17 between. The back-light method produces higher contrast black and white images. Trial tests showed that the back-light 18 method produced less noise in the strain readings and was more stable for high-strain rate tests, therefore this method 19 was adopted in this study. 
1 A 500mm long light with light-emitting diodes was used to ensure constant luminosity. The gauge length on each

2 specimen was specified by two target pieces directly attached to the specimen. The target pieces were specially designed

3 to cater for cross-sectional reduction of all specimens during the tests and stability during the high strain rate tests. As

4 suggested in the video-extensometer user manual, the target pieces were slightly inclined (between $2^{\circ}-5^{\circ}$ ) from the

5 horizontal.

6 The DIC technique was used to obtain the full-field strain measurement of specimens in Test 2, Test 3 and Tests 8-14,

7 see Table 1. DIC is an in situ optical correlation technique which tracks random patterns on the specimen's surface. By

8 comparing two digital images (comprised of pixels) of a specimen's surface taken at different times, a relative

9 displacement in the pixel coordinate system is obtained through correlation analysis of grey-scale intensity values. The

10 displacement is then converted into the physical coordinate system. The strain field is obtained through differentiation

11 of the displacement field. In this technique, a good quality of the surface pattern is of crucial importance. A surface

12 pattern could be an inherent material feature or artificially applied. In this study, a fine speckle pattern was produced by

13 spraying evenly black and white spray paints on the specimen surface. The speckle size in this study varied between

14 3-5 pixels. A detailed presentation on the specimen preparation can be found in reference [9]. Digital images were

15 captured using a Canon EOS 5D Mark III which was fitted with Canon EF - 24-105mm - F/4.0 lens. Depending on the

16 loading rate of the test, images were captured at a frequency ranging between 1 and $5 \mathrm{~Hz}$ with a maximum resolution of

1722 megapixels. Post-processing of image was carried out using the GOM correlate software [32]. The facet size of

$1820 \times 20$ pixels was used in the correlation process to obtain the strain/displacement measurements. The estimated

19 accuracy of DIC measurement obtained in this study is equal to \pm 5 micro strain. More detailed information on using

20 DIC for full-field strain measurement can be found in Sutton et al.[33].

21 All strain-controlled tests discussed in this study were conducted under a closed-loop control (CLC) system in which

22 the strain measured using the extensometer is continuously fed back to the controller of the testing machine and

23 compared with the pre-defined input signal. The difference between the two signals is used to determine the movement

24 of the crosshead. The CLC system, therefore, enables the direct control of the deformation of the specimen, which

25 enhances the precision of the results especially in situations where strain localisation is anticipated.

26 In this study, it was not possible to conduct tests with the CLC system in the tests in which strain was obtained using

27 the DIC technique because strain in these tests was obtained by post-processing the images after the tests were finished.

28 Therefore, these tests were conducted in displacement-control under an open-loop control (OLC) system. In the OLC

29 system, the controller of the machine moves the crosshead as per the fixed pre-defined displacement rate. 


\section{Results and discussion}

\section{3.1. Material characterization}

3 The EDS spectrum given in Figure 1 shows that the weight percentage of the alloying elements in the SMA specimen

4 taken from as-received SMA wire. The composition of the SMA wire was calculated, in atomic percentage, from

5 Figure 1 as $\mathrm{Ni}-47.1 \mathrm{Ti}-9 \mathrm{Nb}$ at\% $\left(\mathrm{Ni}_{47.1} \mathrm{Ti}_{43.8} \mathrm{Nb}_{9}\right)$. The X-ray diffraction (XRD) pattern of the specimen is given in

6 Figure 2. The peaks in Figure 2 can be indexed as a mixture of B2 parent phase (austenite) and $\beta-\mathrm{Nb}$ phase using the

7 lattice parameters: $\mathrm{B} 2, a=0.3018 \mathrm{~nm}$ and $\beta-\mathrm{Nb}, a=0.3296 \mathrm{~nm}[29,32]$.

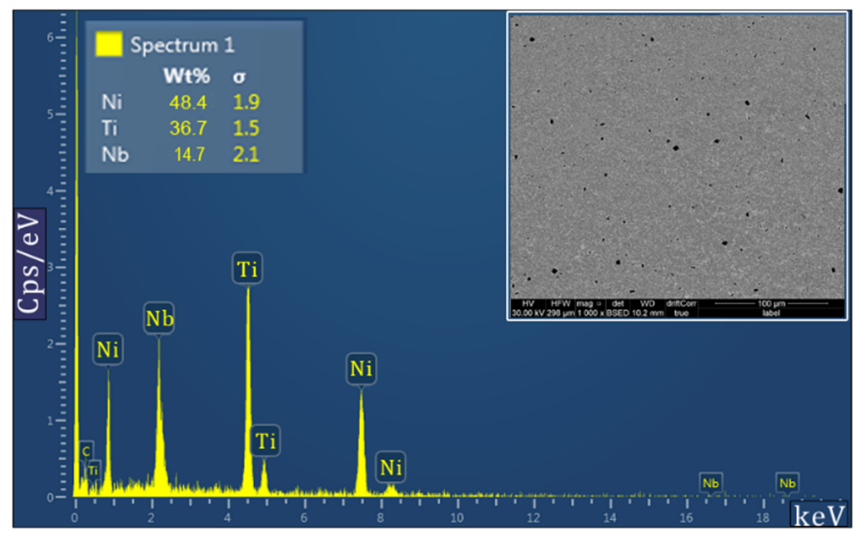

9 Figure 1. EDS analysis of a sample taken from the as-received NiTiNb SMA wire; inset showing the corresponding SEM 10 micrograph.

11

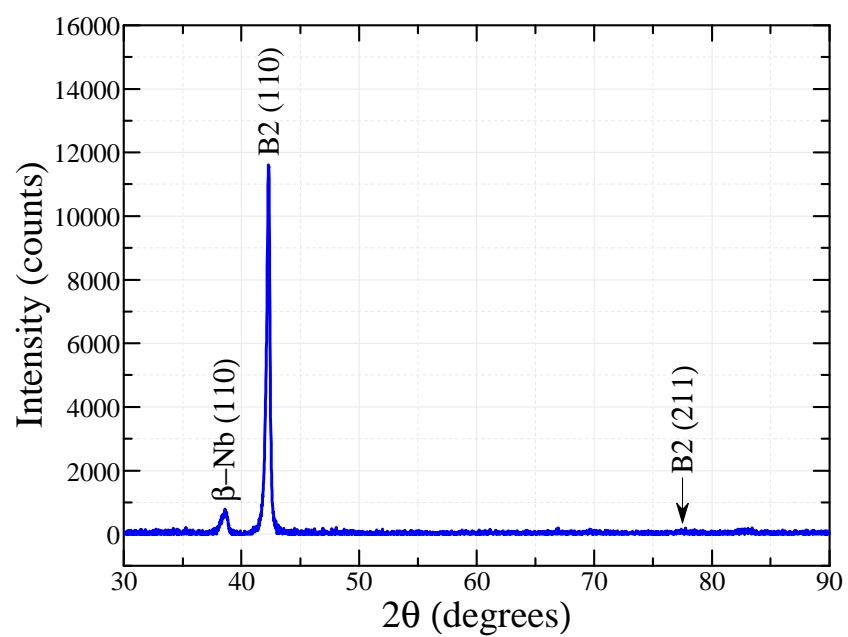

12

13 Figure 2. X-ray diffraction analysis of a sample taken from as-received NiTiNb wire.

15 The DSC curve obtained for the SMA wire is given that is in Figure 3. The start and finish temperatures of the phase 16 transformations were determined from the upright and inverted bell-shaped peaks shown in the DSC curve. The positive 
1 and negative peaks in the DSC curve in Figure 3 are due to the exothermic (upright, positive) and endothermic (inverted,

2 negative) latent heat of transformation. The transformation temperatures for the SMA obtained from the DSC test are 3 given in Table 2, where $M_{s}$ and $M_{f}$ are the martensite start and finish temperature and $A_{s}$ and $A_{f}$ are the austenite start 4 and finish temperature, respectively. From the above given XRD pattern and the DSC results, the as-received NiTiNb 5 SMA wire is assumed to be austenitic at room temperature.

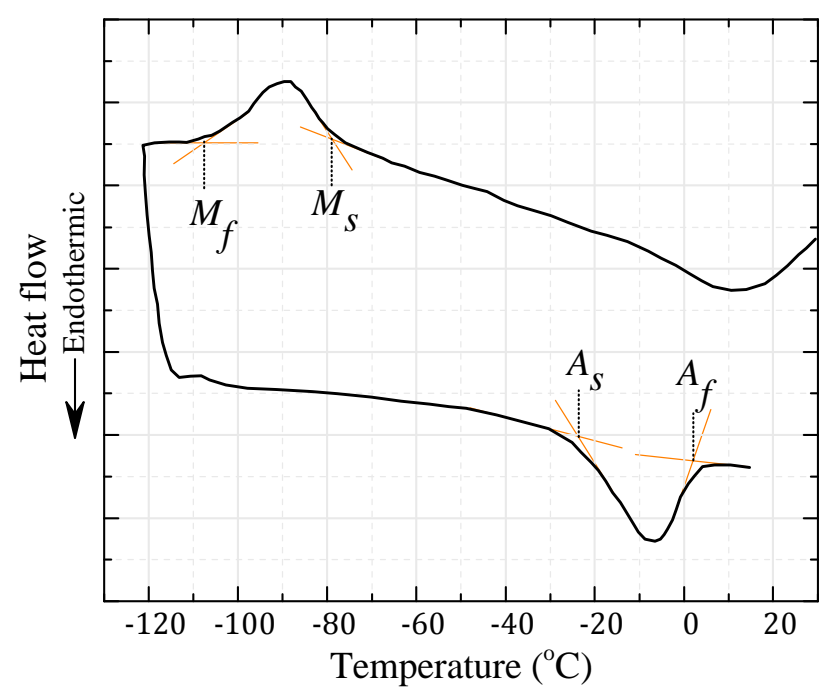

7 Figure 3. DSC curve of the specimen taken from as-received NiTiNb wire.

9 Table 1. Transformation temperature of NiTiNb wires used in this study $\left({ }^{\circ} \mathrm{C}\right)$

\begin{tabular}{cccc}
\hline $\boldsymbol{M}_{\boldsymbol{f}}$ & $\boldsymbol{M}_{\boldsymbol{s}}$ & $\boldsymbol{A}_{\boldsymbol{s}}$ & $\boldsymbol{A}_{\boldsymbol{f}}$ \\
\hline-108 & -80 & -24 & 2 \\
\hline
\end{tabular}

\section{3.2. Uniaxial stress-strain behaviour under monotonic tensile loading}

12 Two virgin NiTiNb wire specimens were tested (Test 1 and Test 2) under monotonic loading to failure. The objectives 13 of these tests were to understand the local behaviour of the wires under monotonic loading and to determine parameters 14 such as modulus of elasticity of the austenite phase $\left(E_{A}\right)$, stress $\left(\sigma_{S}\right)$, and strain $\left(\varepsilon_{s}\right)$ corresponding to the onset of strain 15 localisation, stress $\left(\sigma_{f}\right)$, and strain $\left(\varepsilon_{f}\right)$ corresponding to the point of complete propagation of the localised reorientation 16 bands (i.e. TBs), ultimate stress $\left(\sigma_{u l t}\right)$ and the fracture strain $\left(\varepsilon_{f r}\right)$.

\subsubsection{Nominal stress-elongation response under monotonic loading}

18 Test 1 was conducted in strain-control. 'Strain' $(\delta / \mathrm{L})$ was measured using the video-extensometer over a gauge length

19 (L) of $50 \mathrm{~mm}$, which was specified at the mid height of the specimen using two target pieces. Due to strain localisation 
1 in the material, the strain measured is actually the elongation response averaged over a gauge length and could differ

2 from the local strain in the material. The gauge length was chosen in such a way that it was less than $80 \%$ of the distance

3 between the two grips, the maximum value recommended by ASTM F E8/E8M [35] for wires of uniform sections, but

4 long enough to minimise the strain localisation effect. Test 1 was conducted at a strain rate of $3.3 \times 10^{-3} / \mathrm{s}$, which

5 corresponded to a crosshead speed of $0.2 \mathrm{~mm} / \mathrm{min}$ per $\mathrm{mm}$ of the original gauge length, the maximum value

6 recommended in ASTM F 2516-07 [36] when loading the specimen to failure.

7 Test 2 was conducted in displacement-control at a crosshead speed of $10 \mathrm{~mm} / \mathrm{min}$, which resulted in a strain rate of

8 about $1.5 \times 10^{-3} / \mathrm{s}$. The strain rate in Test 2 was estimated using the total deformation of the specimen measured using

9 crosshead displacement. It is worth noting that the crosshead displacement includes any slip at the grips which is

10 unknown; as a result, the actual strain rate may be less than the estimated rate. In Test 2, full-field strain measurement

11 of the specimen was obtained using DIC. A gauge length of $50 \mathrm{~mm}$ was defined on strain contour maps to compare the

12 stress-elongation response of Test 1 with that of Test 2, see Figure 4.

13 Figure 4 shows a comparison of stress-elongation responses obtained from Tests 1 and 2. Engineering stress and

14 engineering strain are used here and throughout this paper. In Test 1, the specimen was linear elastic up to a strain of

15 about $0.8 \%$. The stress, $\sigma_{s}$ at this point was about $635 \mathrm{MPa}$ and the modulus of elasticity of the SMA specimen was

16 equal to $83 \mathrm{GPa}$. The deviation from the linear path after this point indicated the onset of strain localisation. As the

17 loading continued, stress increased gradually before a stress-drop of $112 \mathrm{MPa}$ was observed at a strain of $2.5 \%$. The

18 stress-drop was accompanied by a sharp clanging sound, which was emitted from the SMA specimen. The drop in the

19 stress is most likely due to the formation of a TB within the gauge length which resulted in a sudden generation of large

20 localised strain. After the stress drop, the stress increased sharply until it reached the plateau level. Thereafter only a

21 gradual increase in the stress was observed until the strain reached $\varepsilon_{f}=8.3 \%$ at which point a sharp change in the slope

22 of the stress-strain curve was noted. The change in the slope is believed to be due to the plastic deformation of oriented

23 martensites in the SMA specimen. The stress-strain behaviour beyond this point appear to be similar to the strain

24 hardening behaviour of common structural steel. 


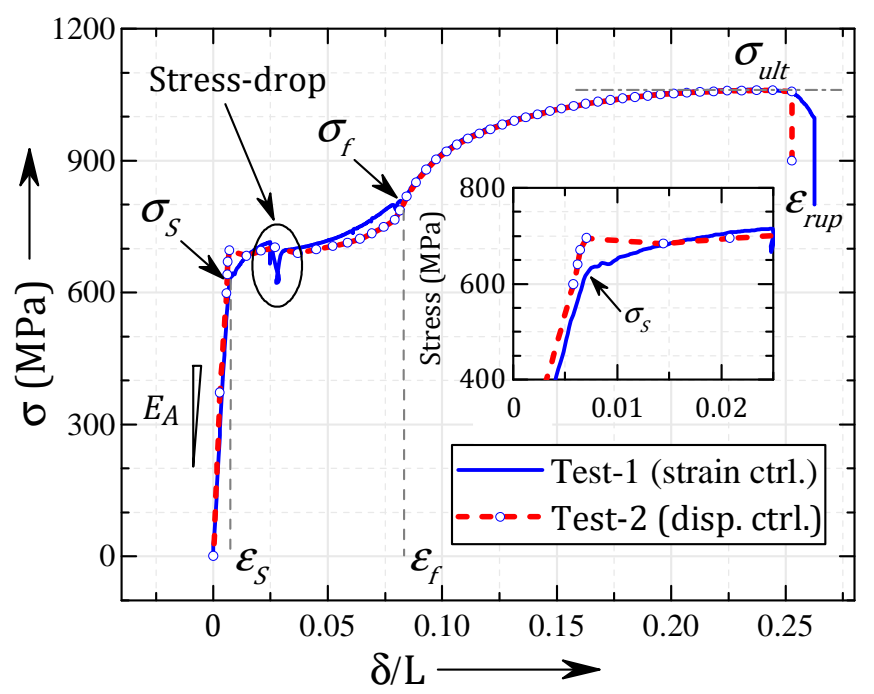

2 Figure 4. Measured nominal stress - elongation response obtained from Test 1 and 2; inset: showing a magnified view of the 3 yield stresses in Test 1 and 2.

5 The stress-elongation response obtained in Test 2 was very similar to that in Test 1 (Figure 4 ). The yield stress, $\sigma_{S}$ in 6 Test 2 appears to be higher at first $(\sim 700 \mathrm{MPa})$, but a close inspection of crosshead measurement revealed that the 7 yielding in Test 2 was actually initiated at $608 \mathrm{MPa}$ (see Figure 5). The reason why $\sigma_{s}$ in Test 2 appear to be higher on 8 the stress-strain curve is that the nucleation of the first TB that corresponded to the onset of yielding was formed near 9 the grip and outside the virtual gauge length. As a result, the strain produced due to nucleation was not recorded by the 10 virtual extensometer. Any increase in the stress after the nucleation of TB appears as a part of linear elastic portion of 11 the stress-elongation curve until either one or more TB extends inside the gauge length or a new TB is nucleated inside 12 the gauge length. Clearly, from this observation the selection of the length and the location of a gauge can significantly 13 influence the measured results.

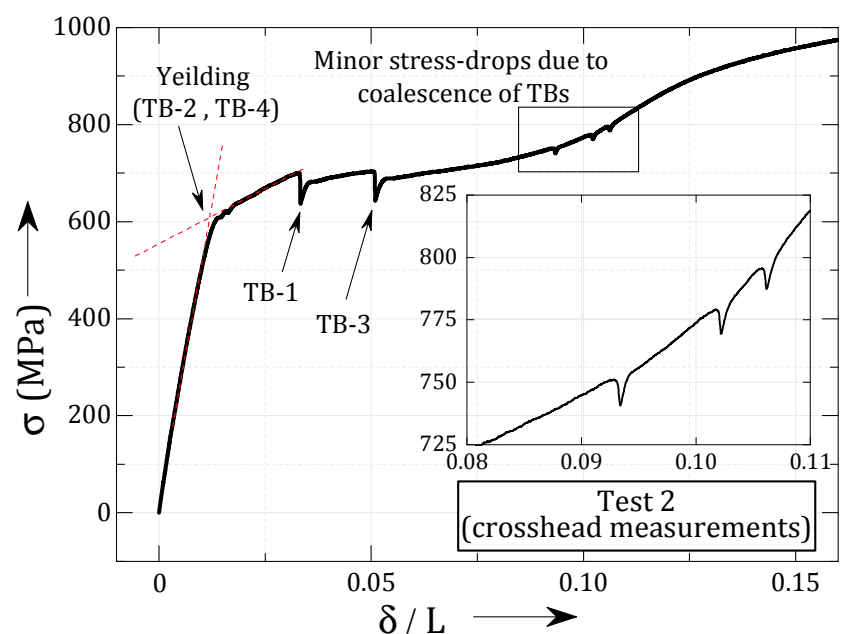

15 Figure 5. Measured nominal stress - crosshead displacement response in Test 2; where $\delta$ is the total crosshead displacement and $16 \mathrm{~L}$ is the total length of the specimen between the grips. 
1 The parameters determined in Tests 1 and 2 are given in Table 2. The slight differences in the yield stress (Table 2) and

2 the slope (Figure 4) in these two tests may be attributed to the thermal effects due to the difference in the strain rates

3 adopted in the two tests. The effect of thermo-mechanical coupling is discussed in detail in the next section. The effect

4 of strain localisation and the location of the gauge length on the apparent yield stress may be insignificant if the test

5 strain rate is very low. This is because, at very low strain rates (e.g. in Test 4 discussed later in Section 3.4) the slope of

6 the stress-strain curve between $\sigma_{s}$ and $\sigma_{f}$ is nearly zero.

8 Table 2. Yield and ultimate stresses and corresponding strains

\begin{tabular}{|c|c|c|c|c|c|c|c|c|c|}
\hline & $\begin{array}{c}\text { Strain measurement } \\
\text { method }\end{array}$ & $\begin{array}{c}\text { Gauge length } \\
{[\mathrm{mm}]}\end{array}$ & $\begin{array}{c}\boldsymbol{E}_{\boldsymbol{A}} \\
{[\mathrm{GPa}]}\end{array}$ & $\begin{array}{c}\sigma_{\boldsymbol{s}} \\
{[\mathrm{MPa}]}\end{array}$ & $\begin{array}{c}\boldsymbol{\varepsilon}_{\boldsymbol{s}} \\
{[\%]}\end{array}$ & $\begin{array}{c}\sigma_{f} \\
{[\mathrm{MPa}]}\end{array}$ & $\begin{array}{c}\boldsymbol{\varepsilon}_{f} \\
{[\%]}\end{array}$ & $\begin{array}{c}\sigma_{u l t} \\
{[\mathrm{MPa}]}\end{array}$ & $\begin{array}{l}\varepsilon_{\text {rup }} \\
{[\%]}\end{array}$ \\
\hline Test 1 & Video-extensometer & 50 & 83 & 635 & 0.77 & 805 & 8.3 & 1059 & $\sim 26$ \\
\hline Test 2 & DIC & 50 & 79 & 608 & 0.79 & 790 & 8.1 & 1060 & $\sim 25$ \\
\hline
\end{tabular}

\section{$11 \quad 3.2 .2 . \quad$ Full-field measurements}

12 The images taken at various stages of Test 2 were first correlated with the reference image (Frame 0), taken at the

13 beginning of the test, to obtain the strain distribution in the specimen using DIC. Individual strain contours of the

14 specimen were then plotted in sequence in Figure 6 to show a temporal evolution of the full-field strain distribution.

15 Apart from 3-6 mm near the top and bottom grips, the entire length of the specimen was investigated. The area of 16 specimen analysed using DIC is termed as area of interest (AOI) in this study. 


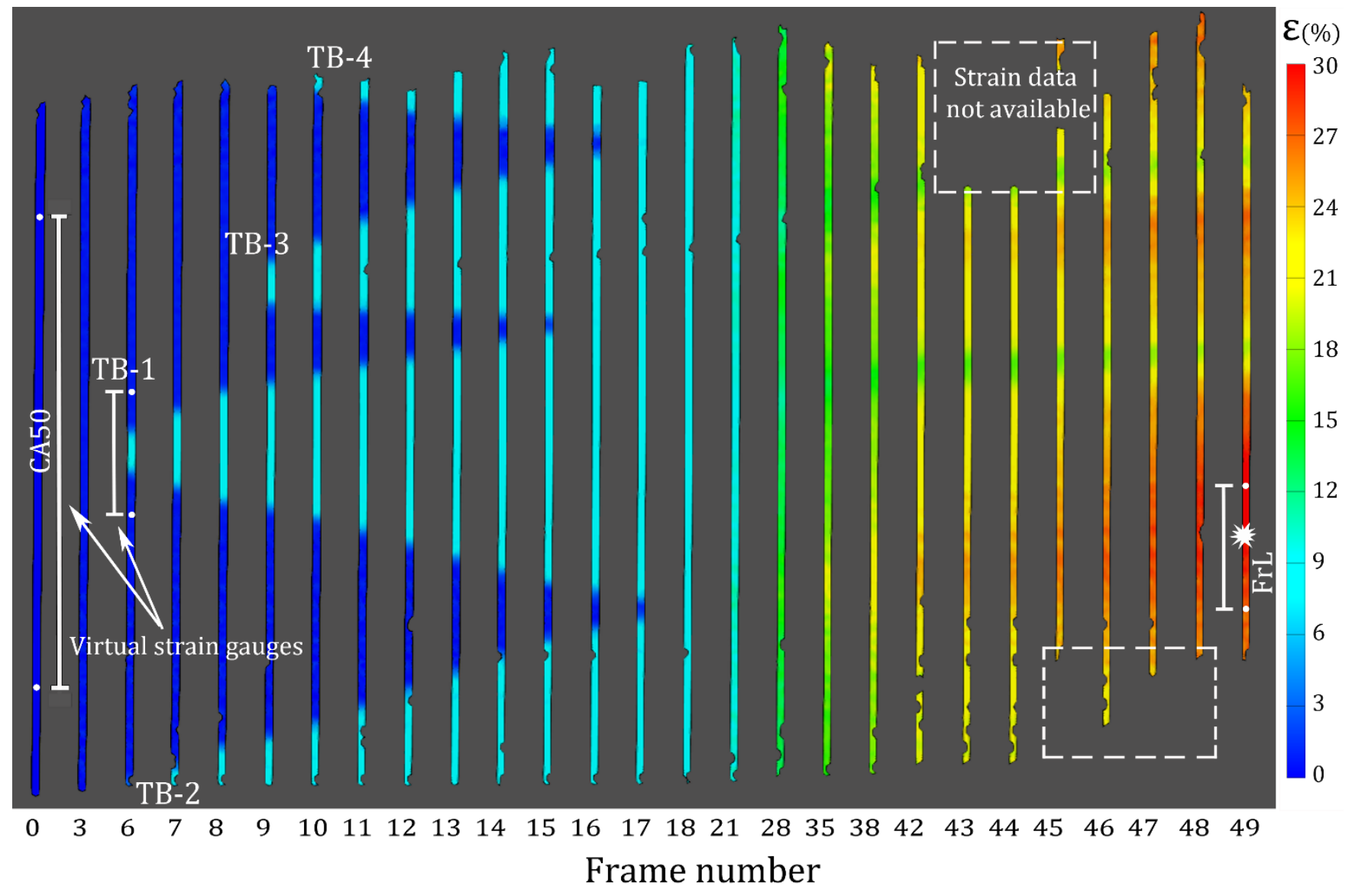

Figure 6. Strain contours showing the formation and evolution of TBs along the length in Test 2.

The nucleation of the first two TBs (TB-3 and TB-4) in Test 2 took place near the bottom and top grip (TBs were marked according to their appearance in the strain contour map) and were outside the AOI shown in Figure 6. The nucleation of TB-2 and TB-4 was identified from the nominal stress-crosshead displacement curve given in Figure 5. TB-2 and TB-4 nucleated at a stress of approximately $608 \mathrm{MPa}$ and lead to the propagation of high-strain fronts towards the centre of the specimen. The high-strain fronts serve as a moving source of heat. The degree of front heating depends on how fast the heat was released, which in turn depends on strain-rate, number of fronts and front velocity, and how fast the heat is removed. The fast release of the latent heat and mechanical dissipative heat during the nucleation process [24] in

11 the tests lead to the increase in front propagation stress (due to Clausius-Clapeyron relation) $[22,23,38]$ which caused a 12 positive slope in the stress-plateau. The stress gradually increased to $702 \mathrm{MPa}$ at which point TB-1 nucleated near the centre of the specimen (See TB-1 in Figure 5 and 6), a relatively cooler region. The nucleation of the TB-1 resulted in a stress-drop of approximately $65 \mathrm{MPa}$ and the reduction of front propagation speed due to the increase in the number of propagating fronts (now 4 in number). The corresponding front propagation stress was also reduced, to $682 \mathrm{MPa}$. As the loading continued, the front propagation stress began to increase again due to the release of latent heat. At a nominal stress of 701 MPa TB-3 nucleated (see TB-3 Figure 5 and 6) which was accompanied by a stress drop of approximately 
$60 \mathrm{MPa}$. The nucleation stress for TB-1 and TB-3 is found to be very similar ( 700 MPa). After TB-3, no new TB was

2 formed. This is because after the formation of TB-3 nucleation stress of the untransformed region, which had become

3 warmer due to proximity of the adjacent TB fronts, was higher than the front propagating stress. Further deformation in

4 the subsequent loading was accommodated by the extension of TBs alone. The extension of TBs reduced the inter-TB

5 spacing resulting in rapid increase in the local temperature of the untransformed region which further increased the front

6 propagation stress. The is evident from rapidly increasing slope of the stress plateau (Figure 5).

7 As the fronts came close to each other, the coalescence of adjacent TBs began to take place one by one. TB-1 and TB-3

8 coalesced first at a stress of $751 \mathrm{MPa}$ followed by TB-3 and TB-4 at $777 \mathrm{MPa}$ and finally TB-1 and TB-2 at $796 \mathrm{MPa}$,

9 see Figure 5. The coalescence of TBs was accompanied by small stress-drops of $10 \mathrm{MPa}$. At the end of the process, the

10 specimen was fully transformed into martensite. The strain in the whole specimen became nearly uniform, having a

11 value of about $8 \%$ (see Frame 18 in Figure 6). The increase of strain from the start of the stress plateau $\left(\sigma_{s}\right)$ to the end

12 of the stress plateau $\left(\sigma_{f}\right)$ was measured equal to $7.3 \%$. Over the stress plateau, the local strain within all TBs was limited

13 to $\sim 8 \%$ (see Figure 7). After the specimen was fully transformed, the strain increased within the whole length of the

14 specimen, albeit non-uniformly, until the fracture of the specimen which occurred just after Frame 49.

15 It may be noted that in Figure 6 the strain in some areas of the specimen (shown in dotted rectangles) could not be 16 analysed during the simple correlation process adopted in this study due to excessive distortion of speckles. Although 17 further analysis could be done to tackle this problem, but this was not undertaken because the results do not affect the 18 conclusions in this study.

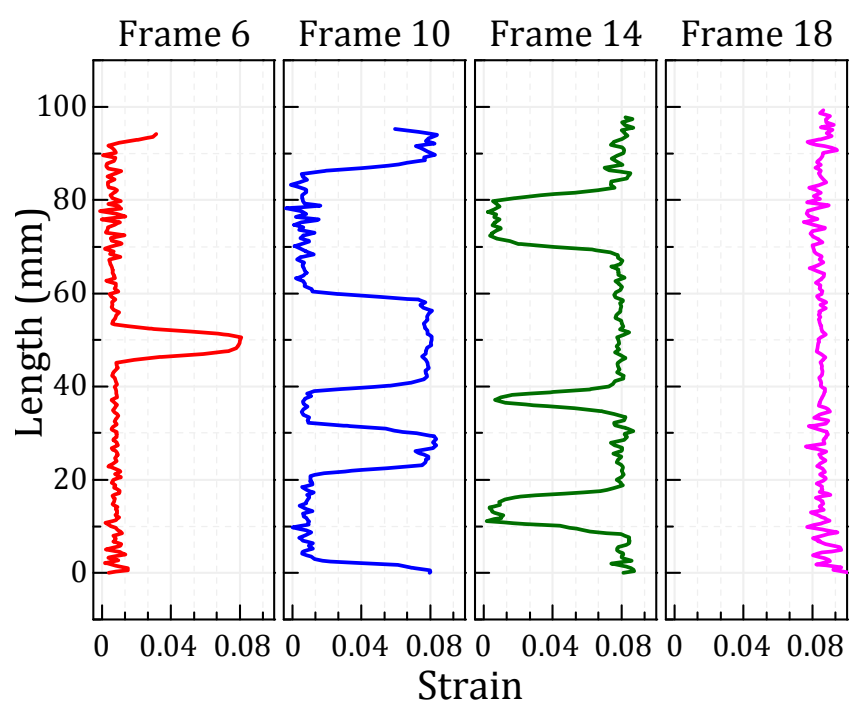

20 Figure 7. Strain distribution along the length of the specimen at various stages from initiation to complete propagation of TBs in $21 \quad$ Test 2. 
1 Unlike common metals such as mild steel, a significant non-uniformity in the strain distribution in the form Lüders-like

2 bands are observed in NiTiNb wires immediately after yielding. Similar observations have been reported by researchers

3 for other types of SMAs such as in NiTi wires [38] and NiTi flat coupons [26]. Strain localisation in the form of Lüders-

4 like bands have been shown to interact with structural instabilities [24], such as plastic column buckling and collapse

5 are influenced by the extent of local strain (Lüders strain) [39]. Compared to NiTi wires in which the nucleation of TBs

6 typically produces a local strain of 5-6\% within the TBs [26], a strain of $\sim 8 \%$ is produced almost instantaneously in the

7 NiTiNb wires tested in this study. For structural applications of SMAs such as NiTiNb SMAs strain localisation is an

8 important aspect to consider in the design process. Non-uniform strain distribution can be a serious problem in some

9 structural engineering applications for e.g. in applications where NiTiNb SMAs are used as reinforcing bars

10 nonhomogeneous strain distribution may lead to completely different deformation/crack pattern than expected for

11 homogeneous strain distribution. Similarly, 'Plastic hinges could form at locations other than expected or designed.

12 Bond behaviour of SMA rebars could also be affected due to strain localisation.

\section{3.3. Uniaxial stress-strain behaviour under cyclic tensile loading}

14 To investigate the stress-elongation response of $\mathrm{NiTiNb}$ wire under cyclic loading, a virgin specimen was cyclically

15 loaded and unloaded under displacement-control in Test 3. The loading and unloading of specimen were carried out as

16 shown in Figure 8. In the $1^{\text {st }}$ cycle, the specimen was loaded from Point a to $\mathrm{d}$ and then unloaded to zero stress (Point $\mathrm{e}$

17 in Figure 8). In the $2^{\text {nd }}$ cycle, specimen was loaded from Point e to $g$ and unloaded again to zero stress (Point $\mathrm{i}$ in

18 Figure 8). And lastly, the specimen was loaded from Point i to rupture at Point k. The elongation response given in

19 Figure 8 was measured using DIC over a virtual gauge length of $50 \mathrm{~mm}$ at the mid-height of the specimen (see CA50

20 in Figure 9). The strain rate adopted for the test was $1.5 \times 10^{-3} / \mathrm{s}$. In order to reduce the computational time in the post-

21 processing of images, the specimen was subjected to only two cycles before loading it to fracture. The yielding of the

22 specimen occurred at Point $b$, which was determined from stress vs test time plot shown in the inset in Figure 8. 


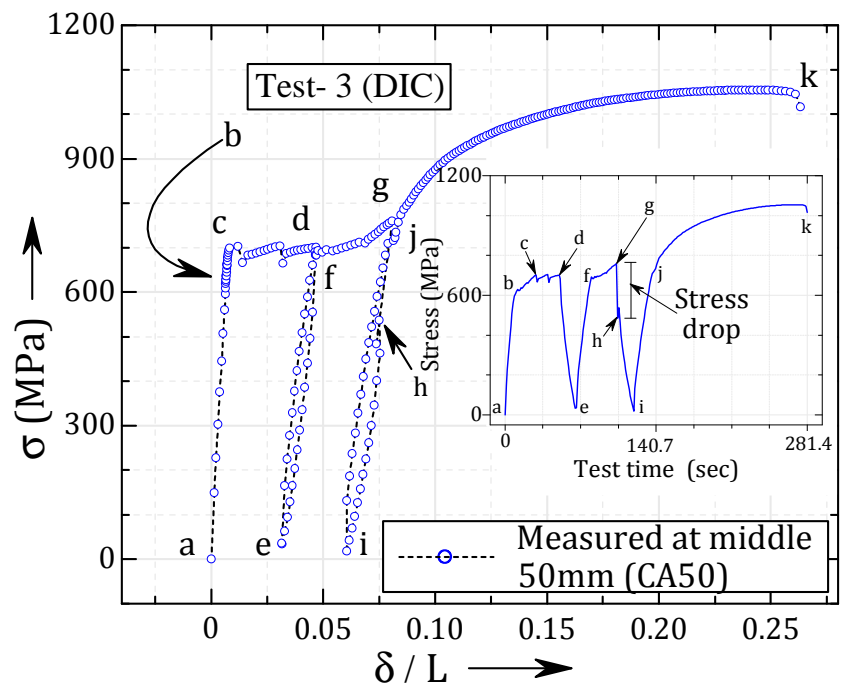

2 Figure 8. Measured nominal stress - elongation response of a virgin NiTiNb wire specimen in Test 3.

\subsubsection{Full-field measurements}

5 Figure 9 presents the full-field strain distribution of the specimen in Test 3. For brevity, only selected contours between 6 the start of the test and the complete propagation of transformation bands (i.e. from Point a to $\mathrm{j}$ in Figure 8) are shown 7 here. In Figure 8, Frame 0 represents the start of the test; unloading of the specimen in the $1^{\text {st }}$ cycle was initiated in 8 Frame 48; Frames 62 to 99 represent the start and completion of the $2^{\text {nd }}$ loading and unloading cycle. The final loading 9 step to fracture started from Frame 112.

10 As in Tests 1 and 2, multiple TBs were also formed in Test 3. The nucleation of first two TBs (TB-1 and TB-2a) took

11 place near the top and bottom grips. Due to the uniform section of the specimen and relative stress concentration at the 12 grips, it appears that nucleation of first TB is generally initiated near the grips. The nucleation of TBs near the grip 13 created two propagating fronts which progressed towards the centre of the specimen. As the loading continued the 14 nominal stress increased due to increase in the front propagation stress. At a stress of $704 \mathrm{MPa}$, the nucleation of third 15 TB-2b took place which was accompanied by a stress drop of $68 \mathrm{MPa}$. After the stress-drop, the stress rapidly returned 16 to plateau level, but the front propagation stress was reduced to $684 \mathrm{MPa}$. With the subsequent loading front propagation stress increased to $706 \mathrm{MPa}$ at which point TB-3 nucleated at the centre of the specimen. The nucleation of TB-3 was 18 accompanied with a stress drop of $68 \mathrm{MPa}$. After TB-3, no more TBs were formed.

19 All four TBs in Test 3 were formed during the $1^{\text {st }}$ loading cycle (Point a $-\mathrm{d}$ in Figure 8 ). The limiting strain, $\varepsilon_{T r}$ in all 20 the TBs was about 8\%, the same as in Test 2. On unloading (Point $\mathrm{d}$ to e in Figure 8), the strains in the TBs (and out of 21 them) were reduced, but the size of the TBs remained almost the same (see TB-2b and TB-3 in Figure 9). The strain 

recorded in the individual TBs was about $2 \%$. This difference is due to partial transformation of CA50.

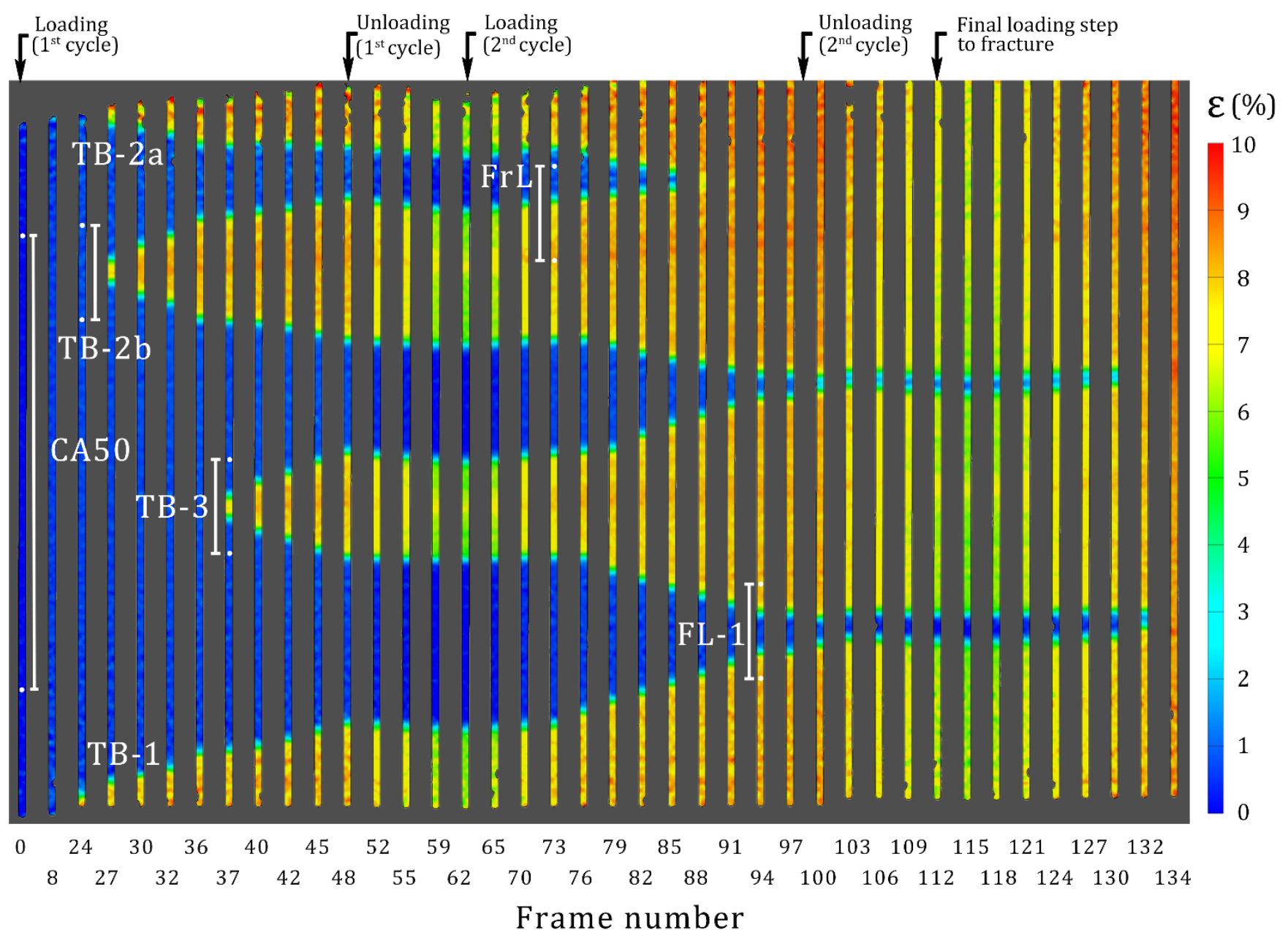

Figure 9. Strain contour of Test 3 specimen showing evolution of TBs during loading and unloading for strain range of 0-9\%.

The residual strain (strain between Point a and e in Figure 8) measured over the $50 \mathrm{~mm}$ gauge length (CA50) was approximately $3.1 \%$ and in the TBs, it was $6 \%$. A more detailed discussion on residual strain retained on unloading is carried out in Section 3.4.

On re-loading the specimen in the $2^{\text {nd }}$ cycle (Point e to $g$ in Figure 8), the deformation of the specimen was first accommodated by the strain produced within the TBs, which were formed in the previous cycle, until a limiting value of strain, $\varepsilon_{T r}$, was reached in the TBs (see Figure 9 and Figure 10), after which the broadening of the TBs started. This indicates that on reloading a partially transformed SMA, un-transformed regions remain elastic until the strain in the previously formed bands reach the limiting strain of transformation, $\varepsilon_{T r}$. The 'reactivation' of the front propagation was accompanied by minor stress drops of $10 \mathrm{MPa}$. As the TBs started to extend front propagation stress started to gradually 
1 increase which is noted by observing the increasing slope of the stress plateau. As the fronts came closer, the coalescence

2 of the TBs started to take place one by one. This coalescence process was accompanied by a stress drops of $10 \mathrm{MPa}$.

3 A significant stress-drop of about $300 \mathrm{MPa}$ was observed just before unloading of the specimen in the $2^{\text {nd }}$ cycle. This

4 stress-drop between Point $\mathrm{g}$ and $\mathrm{h}$ (see inset in Figure 8) could be due to the slip at the grips because of extension of TB

5 inside the grips. During the nucleation of a TB, the local cross-sectional area of the wire is reduced considerably and

6 instantaneously. If the reduction of the cross-sectional area takes place near/inside the grips, it could result in a

7 considerable amount of slip, especially if body over wedge grips are used, as is the case in this study. Therefore, two

8 situations of stress-drop are highlighted in this test. 1) nucleation of TB (away from the grips) which is accompanied by

9 a sudden generation of large localised strain resulting in some level of stress-drop. 2) nucleation or extension of TB

10 inside the grips results in a significantly higher stress-drop as compared to TB formed away from grips. Thinning of

11 cross-section due to nucleation or extension of TB inside the anchors should therefore be considered while designing

12 anchoring system for such SMA wires/cables.

13 At the end of the $2^{\text {nd }}$ loading cycle, the specimen was still partially transformed, and some regions of the specimen were 14 still in the elastic phase (e.g. location FL-1 shown in Figure 9). Their coalescence with the adjoining band(s) in the $3^{\text {rd }}$ 15 loading cycle marked the complete transformation of the specimen to martensite phase.

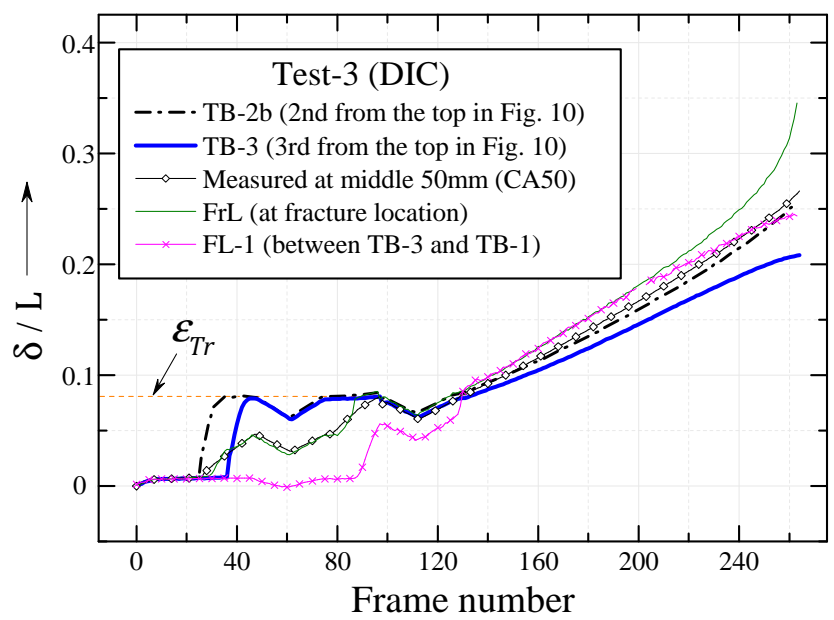

17 Figure 10. Development of strains at TB-2b, TB-3, FrL, FL-1 and CA50 in Test 3, see Figure 9 for the location of gauges.

\subsubsection{Nominal stress-elongation response under cyclic loading}

19 Due to the non-uniform strain evolution during the SIM phase transformation, the stress- 'strain' behaviour measured at different locations of the specimen can differ quite significantly. This is evident in Figure 11 in which stress-elongation 21 curves were plotted by measuring the elongation response locally at four different locations (TB-2b, TB-3, FrL and 
1 FL-1, see Figure 9) on the specimen. The strains were measured using the same virtual gauge length of $10 \mathrm{~mm}(=5 \mathrm{x}$ 2 diameter of SMA wire).
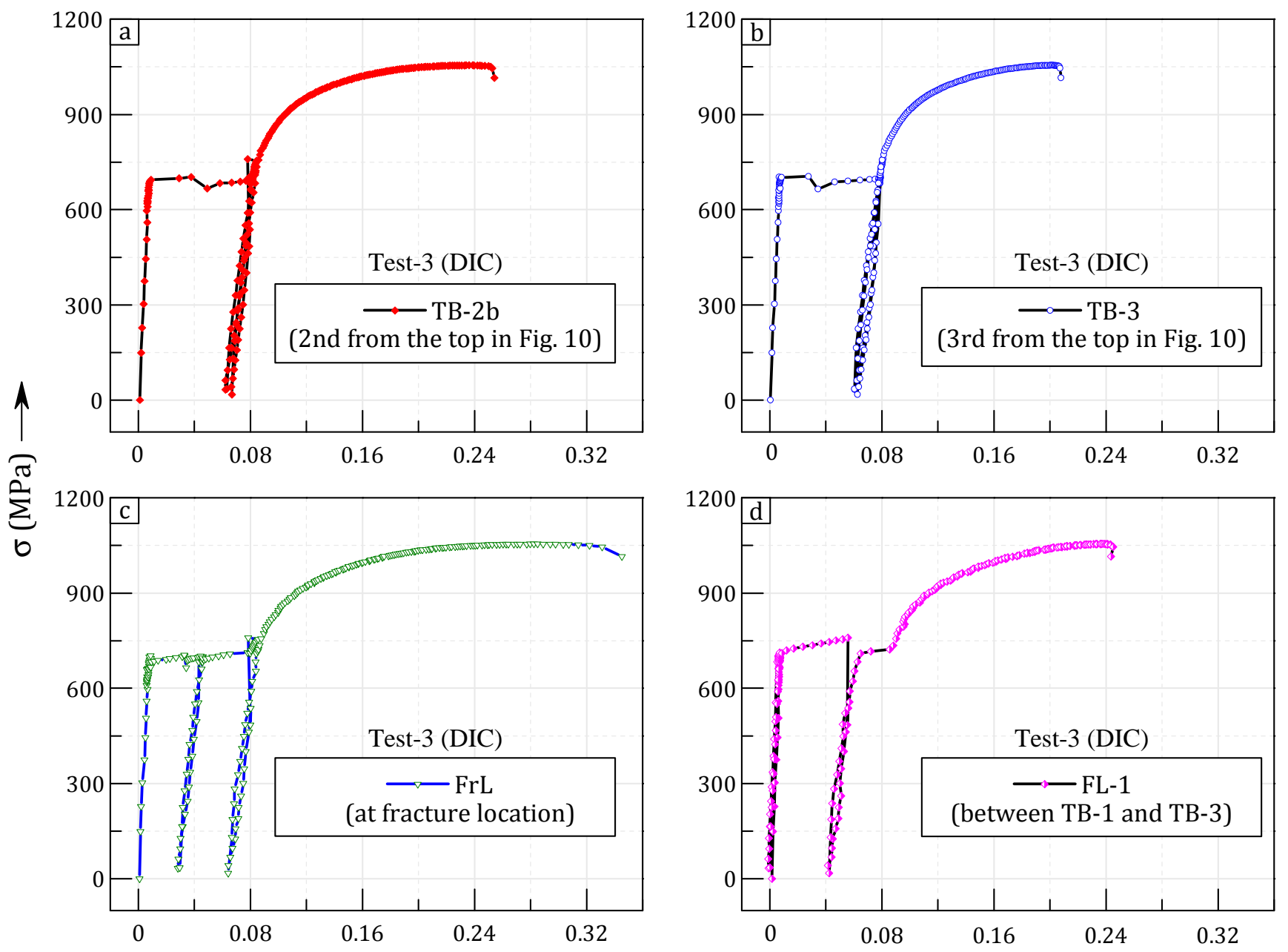

$\delta / \mathrm{L}$

Figure 11. Nominal stress - elongation response measured at (a) TB-2b; (b) TB-3; (c) fracture location (FrL); (d) at location FL-1; (region between TB-1 and TB-3); (see Figure 9 for locations of TB-2b, TB-3, FrL and FL-1).

In Figure 9, it can be seen that TB-2b and TB-3 were fully transformed by the end of the $1^{\text {st }}$ loading cycle so their maximum strains were equal to the limiting strain of transformation $\left(\sim 8 \%=\varepsilon_{T r}\right)$ until the whole specimen was fully transformed. Consequently, the unloading branch in the $1^{\text {st }}$ cycle, the reloading and unloading branches in the $2^{\text {nd }}$ cycle

9 and the loading branch in the last loading (to failure) are almost the same. Contrary to TB-2b and TB-3, at the fracture 10 location (FrL) the specimen was only partially transformed at the end of the $1^{\text {st }}$ loading cycle with an average measured 11 strain of $4.5 \%$ within the gauge length which is much smaller than $\sim 8 \%$ measured within the transformed region. The 12 unloading in the $1^{\text {st }}$ loading cycle took place at a strain of $4.5 \%$. Upon unloading, a residual strain of about $2.8 \%$ was 13 retained at FrL, which compares with $\sim 6 \%$ in the transformed region (TB- $2 \mathrm{~b}$ and TB-3). In the $2^{\text {nd }}$ loading cycle, strain 
1 in the specimen increased but was limited to $\varepsilon_{T r}$ until complete transformation of the specimen. Unloading in $2^{\text {nd }}$ loading

2 cycle took place at a strain of $\sim 8 \%\left(=\varepsilon_{T r}\right)$ due to the complete transformation within this gauge length at this stage.

3 Location FL-1 remained linear elastic within the $1^{\text {st }}$ cycle, so that the unloading branch (started at about $0.8 \%$ strain)

4 overlaps the loading one. The reloading of the $2^{\text {nd }}$ cycle followed the initial elastic branch, but it reached yielding during

5 the process and unloading took place at a strain of $5.5 \%$ with a residual strain of $4.2 \%$. FL was fully transformed only

6 in the $3^{\text {rd }}$ loading cycle.

7 Considering that the nucleation of TBs in SMA wires takes place non-homogeneously along the length, a care must be 8 taken in choosing an appropriate gauge length for obtaining a correct stress-elongation response of an SMA. From the 9 above discussion, it is clear that under cyclic loading in particular, both the location and the length of the gauge have 10 great influence on the measured stress-strain behaviour of SMA wires.

\section{$11 \quad 3.4$. Effect of strain rate}

12 Two sets of tests were conducted to investigate the effect of strain rate on the cyclic behaviour of NiTiNb wires at room

13 temperature (see Table 1). Tests 4-7 were conducted under strain-control and Tests 8-14 in displacement-control. In 14 Tests 4-7, strain was measured over a fixed gauge length of $50 \mathrm{~mm}$ at the mid-height of the specimens using video15 extensometer. In Tests 8-14, the full-field strain contour maps of the specimens were obtained using DIC.

16 The stress-elongation response obtained in Tests $4-7$ are shown in Figure 12(a). Specimens were first loaded to 6\% 17 strain and then fully unloaded. Loading and unloading of specimens in each test was carried out at the same rate. Test 4 18 was carried out at a very low strain rate of $3.3 \times 10^{-5} / \mathrm{s}$. The yield stress (upper yield) in Test 4 was equal to $602 \mathrm{MPa}$.

19 The onset of yielding, which indicated the nucleation of first TB, was accompanied by a small stress-drop (30 MPa).

20 After the first stress-drop, a completely flat stress plateau was observed. The stress plateau was maintained at a stress

21 level of $585 \mathrm{MPa}$. As the test was conducted at a very slow strain-rate (near isothermal conditions), the heat 22 accumulation in the specimen was very low which resulted in stable front propagation stress and therefore it led to a flat stress plateau. Over the stress plateau region, no major stress drop was observed, which indicated the deformation in the specimen was most likely accommodated by the gradual growth of the TB formed at the start of the stress plateau. At the end of the loading step, the specimen was unloaded and unlike superelastic SMAs, a large residual strain of about 
$14.8 \%$ of the strain was retained on unloading of which about $62.5 \%$ recovered on heating (due to shape memory effect),

2 leaving behind a net plastic strain of only $1.8 \%$.

3 Test 5 was performed at a slightly higher strain rate of $3.3 \times 10^{-4} / \mathrm{s}$. The yield stress $(610 \mathrm{MPa})$ in Test 5 was only slightly 4 higher than that in Test 4. A small drop in stress at the onset of yielding was also noted in Test 5. After yielding, stress 5 continued to increase but only gradually. The slight increase in the plateau slope is due to the release of latent heat. At 6 a stress of $630 \mathrm{MPa}$ a stress-drop of about $30 \mathrm{MPa}$ was recorded at a strain of $1.7 \%$, which hints towards the nucleation 7 of a new TB. The nucleation of a new TB results in the increase of the number of fronts and reduction in the front 8 propagation speed due to which the degree of heat released during the front propagation was reduced. A near isothermal 9 environment was created and a flat stress plateau in the subsequent loading was observed. Upon unloading the specimen, 10 a residual strain was about $4 \%$, similar to that in Test 4 was recorded.

11 In Test 6 , the specimen was loaded at a strain rate of $3.3 \times 10^{-3} / \mathrm{s}$ which is 100 times faster than the strain rate adopted in

12 Test 4 . The yield stress in Test 6 , about $630 \mathrm{MPa}$, was slightly higher than the previous test (610 MPa). The slope of the 13 stress plateau, immediately after the yielding, was significantly higher than that in Tests 4 but comparable to Test 5 . At 14 a strain of $2.7 \%$, a stress-drop of $100 \mathrm{MPa}$ was recorded which is nearly 3.5 times larger than that in Test 5 . After the 15 stress-drop, stress increased rapidly until it reached the plateau level thereafter it increased only gradually until unloading 16 was carried out. The slope of the stress plateau after the stress drop was relatively less than slope of the stress-plateau 17 before the stress-drop due higher number of fronts. The residual strain upon unloading was approximately $3.6 \%$, slightly 18 less than the residual strain measured in Test 5. 

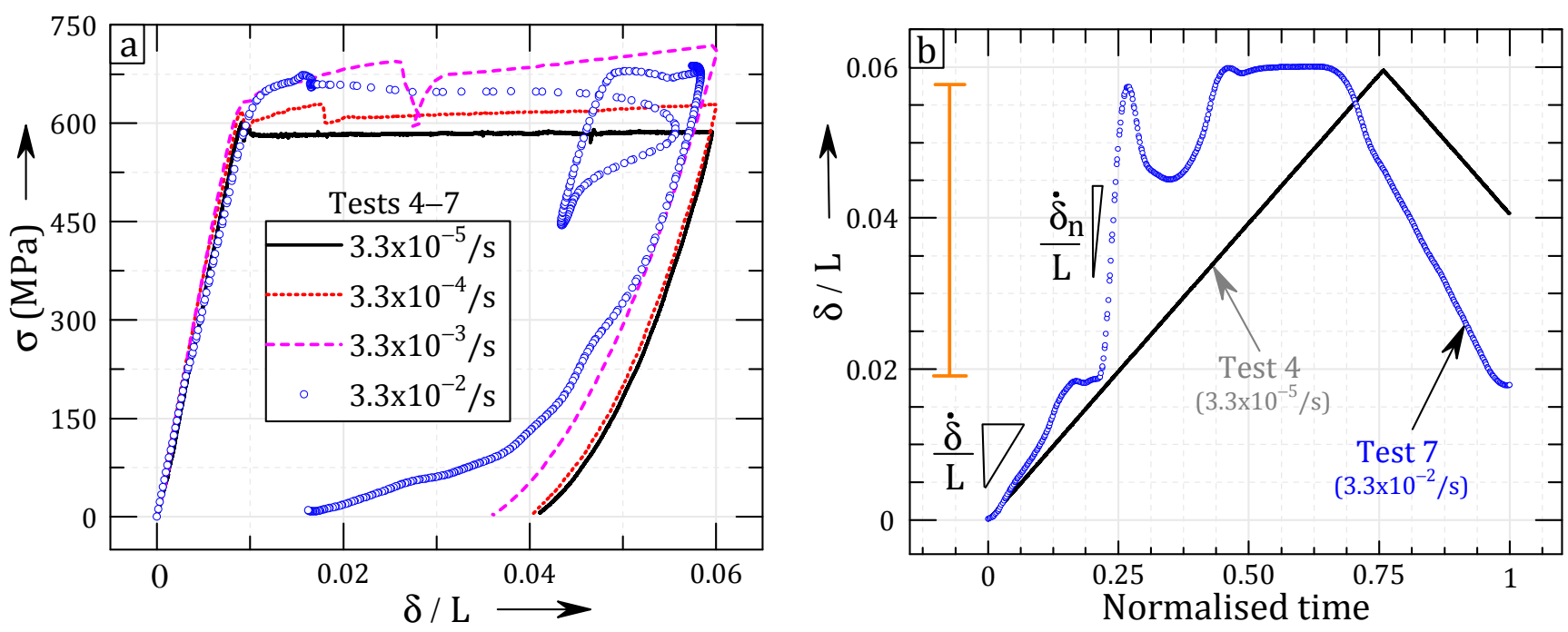

2 Figure 12. The effect of strain rate: (a) on stress-elongation response of virgin NiTiNb specimens; (b) comparison of 'strain'

$3(\delta / \mathrm{L})$ vs normalised time between Tests 4 and $7\left(\dot{\delta} / \mathrm{L}\right.$ is the nominal strain rate of test; and $\left(\dot{\delta}_{\mathrm{n}} / \mathrm{L}\right)$ is the estimated strain rate

4 during the nucleation).

The last test of the first set, Test 7 , was conducted at strain rate of $3.3 \times 10^{-2} / \mathrm{s}$. The yield stress was similar to that in Test 6 , but as the specimen started to yield, a relatively large strain $(\sim 3.9 \%)$ was almost instantly generated within the gauge length. The rate at which this strain was produced within the gauge length during the nucleation of $\mathrm{TB}(\mathrm{s})$ was equal to $2.5 \times 10^{-1} / \mathrm{s}$, which exceeded the originally defined strain rate of $3.3 \times 10^{-2} / \mathrm{s}$ by 7.5 times; see Figure $12(\mathrm{~b})$. This implies that the front propagation speed of $\mathrm{TB}(\mathrm{s})$ was very high and the deformation produced by nucleation and growth of TB exceeded the applied deformation. As the rate at which the strain was produced exceeded the originally defined strain rate for the test, the CLC system of the machine reversed the direction of the crosshead movement to stabilise the strain rate back to the predefined rate. The crosshead returned to the displacement location (strain of $4.3 \%$ ) corresponding to the pre-defined strain rate. The reverse movement of the crosshead caused a partial unloading of the specimen. A stress-drop of about $230 \mathrm{MPa}$ was recorded during this process see Figure 12(a) and (b). Once the strain rate was stabilised, the stress increased rapidly as it returned to plateau level and thereafter gradually until the unloading of the specimen was carried out at a strain amplitude of $6 \%$.

Upon unloading, a residual strain of only $1.6 \%$ was recorded in the specimen, which is significantly less than the

19 previous tests (Test 4 to Test 6). The reason for this response is that the released heat in the loading process did not have enough time to transfer (i.e. loading time is much shorter than heat convection time) out due to high strain rate and therefore it was carried to unloading process, resulting in specimen's temperature much higher than the ambient temperature. From the strain recovery achieved on unloading, it is most likely that the temperature of the specimen was 
1 either very close to $80^{\circ} \mathrm{C}\left(A_{f}\right.$ of the deformed NiTiNb specimen based on the finding in [9]) or well above it. The

2 forward transformation, which is endothermic process, appears to have insignificant effect on cooling of specimen. The

3 retained residual strain is believed to be mostly the permanent unrecoverable strain.

4 The results obtained from Tests $4-7$ highlight the high level of sensitivity NiTiNb SMAs show towards the strain rates.

5 With the increase of strain rate, the strain produced during the nucleation process is increased, which consequently

6 results in a large stress-drops. The large stress-drop during the nucleation process could pose serious problems in

7 practical applications. For example, a sudden generation of large strain in NiTiNb wires/cables used as an energy

8 dissipation fuse in tension braces for seismic applications, would not only lead to significant deformation of the structure

9 but it would also mean that the stress drop in SMA tension brace would need to be accommodated by other member of

10 the structure which may or may not be able to resist the additional loads. Another aspect of this phenomena that needs

11 to be taken account of is the rate at which the strain is produced during the nucleation process. At high loading rates

12 sudden stress-drops might result in dynamic effect during the stress transfer.

13 The results from Tests 4-7 also showed that strain recovery in NiTiNb SMA wires is significantly affected by the 14 unloading strain rate. Upon unloading, the strain recovery in the specimen tested at a strain rate of $3.3 \times 10^{-2} / \mathrm{s}($ Test 7$)$ 15 was $73 \%$ more than strain recovered in specimen tested at a slower strain rate of $3.3 \times 10^{-5} / \mathrm{s}$ (Test 1$)$. This is an important 16 observation for heat-activated prestressing applications of NiTiNb SMAs. The consequence of large strain recovery on 17 unloading is that the recovery stress (prestress) developed on heating after pre-straining the SMA could be significantly 18 less. Further discussion on this phenomenon is presented elsewhere [9].

19 Apart from the stress-drops, which are more prominent in strain-controlled tests (Tests $4-7$ ) a similar behaviour was

20 observed in the second set of tests, Tests $8-14$, which were conducted in displacement control. In a displacement-

21 controlled test, it may be difficult to record the actual stress-drop if the strain in the TBs is produced at a rate higher 22 than the rate of crosshead movement. 


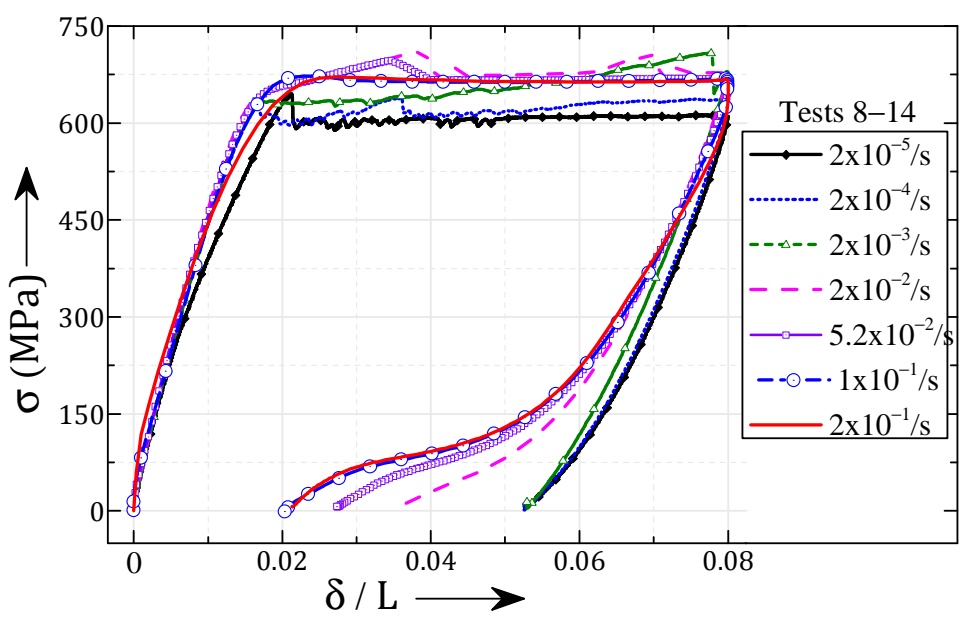

Figure 13. Effect of strain rate on the nominal stress- elongation response of virgin NiTiNb specimens (Tests 8-14, displacement-controlled tests, where $\delta$ is the total crosshead displacement in this case and $\mathrm{L}$ is the total length of the specimen).

\subsubsection{Full-field measurements}

The full-field strain distribution of the specimens deformed in Test 8-14 is presented in Figure 14. For brevity, strain contours were plotted only for the point of maximum strain applied during the loading cycle (i.e. just before the unloading was carried out), in Figure 14(a), and for the point at which the specimens were fully unloaded (i.e. at zerostress level), in Figure 14(b).

In Tests 8-14, TB(s) were first formed either near the bottom grip or near the top grip. The formation of transformation bands (TBs) is directly linked to stress concentration from the grain scale to the specimen scale. The location of formation of TBs can therefore take place anywhere in the specimen and can vary from test to test. In specimens with uniform cross-section, the formation of first TBs generally takes place near the grips due to the stress concentration, but it is not always true. All specimens in Tests $8-14$ were partially transformed (see Figure 14). The maximum strain in all the TBs was limited to the limiting strain of transformation $\left(\varepsilon_{T r}\right)$. Figure 14 suggests that the number of TBs formed in the SMA first increases with the increase of strain-rate and then it decreases. At a very slow strain rate $\left(\dot{\varepsilon}=2 \times 10^{-5} / \mathrm{s}\right.$;

17 Test 8) only one TB, near the bottom grip, was formed which extended to the mid-height of the specimen. At low strain rates the front propagation speed is low and so is the heat accumulation. A near isothermal condition is established.

Consequently, front propagation stress does not increase (or increases only very slowly). As long as the front propagation stress is lower than the nucleation stress no new TB is nucleated in the specimen. With the increase of strain rate, the rate of heat release during the front propagation increases. As a result, front propagation stress exceeds the nucleation stress number of times over the stress plateau region which results in the increase of number of TBs formed during SIM 
1 phase transformation. The number of TBs increased from two in Test $9\left(\dot{\varepsilon}=2 \times 10^{-4} / \mathrm{s}\right)$ to four in Test $11\left(\dot{\varepsilon}=2 \times 10^{-2} / \mathrm{s}\right)$.

2 In Test 11 the top two TBs coalesced just before the unloading took place. After Test 11, as the strain rate increased the 3 number of TBs formed in the specimens reduced. At strain rate was increased further, $\dot{\varepsilon}>1 \times 10^{-1} / \mathrm{s}$ (Test $13 \& 14$ ), the 4 total number of TBs formed in the specimens was just one. In these tests there was no indication of increase in the front 5 propagation stress (no hardening was observed) instead a completely flat stress plateau was formed at a stress of $6 \sim 660 \mathrm{MPa}$. One possible explanation of this material behaviour could be that at high strain rates several 'micro' TBs 7 are formed in close vicinity during the nucleation process which coalesce immediately to form one large TB, and in the 8 process large amount of strain is produced instantaneously to accommodate the applied deformation. In fact, in Test 7 9 it was observed that the amount of strain released during nucleation process was much larger than applied load, and the 10 rate at which this strain was produced was also greater than the applied strain rate. If the applied strain rate and the rate 11 at which the strain is produced in the nucleation process are comparable, no stress drops will be observed in the stress12 elongation curve. 

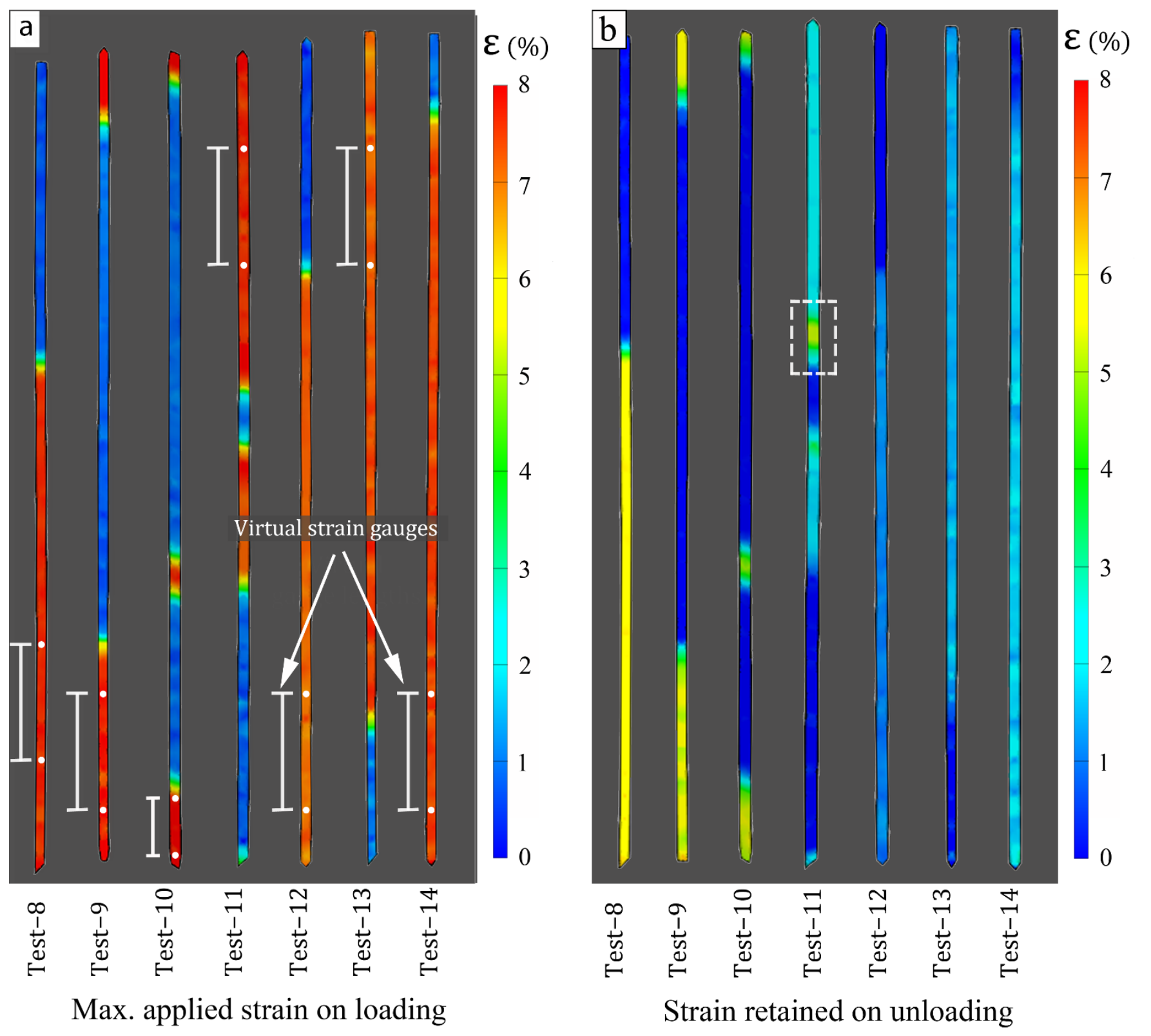

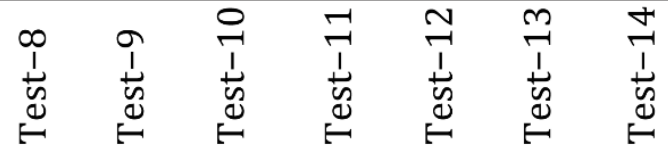

Max. applied strain on loading $\varepsilon(\%)$

2

Figure 14. Full field strain distribution of NiTiNb specimens tested at different strain rates; a) maximum strain in specimens at the

5 In Figure 12(a), it was shown that as the strain rate increases beyond $3.3 \times 10^{-4} / \mathrm{s}$, the strain recovery on unloading also

6 begins to increase. In Figure 15, however, the strain recovery begins to increase only when strain rate is increased

7 beyond $2 \times 10^{-3} / \mathrm{s}$. The difference in the two values arises due to the difference in the measurement method. For

8 Figure 12(a), the strain rate was estimated using the actual deformation of the specimen within the gauge length using

9 CLC method, while for Figure 15, the strain rate was estimated using the crosshead displacement which includes any

10 slip within the grips. As a result, the strain rate given in Figure 15 may be significantly higher than the actual strain rate

11 in the specimens. Figure 15 also demonstrates that there is an upper limit to the increase in strain recovery due to

12 increased strain rate. 
1 In Figure 14, it is clear that the strain recovery in the TBs was significantly different. More strain was recovered in TBs

2 at higher strain rates. The effect of strain rate on strain recovery is given in Figure 15. Strain recovery was measured 3 using the virtual gauge length, which were marked on fully transformed section of the specimens (See Figure 14). Gauge 4 length of $10 \mathrm{~mm}$ was chosen for all tests except for Test 10 for which a virtual gauge length of only $6 \mathrm{~mm}$ was used.

5 This is because the maximum length of TBs in Test 10 was only $6 \mathrm{~mm}$.

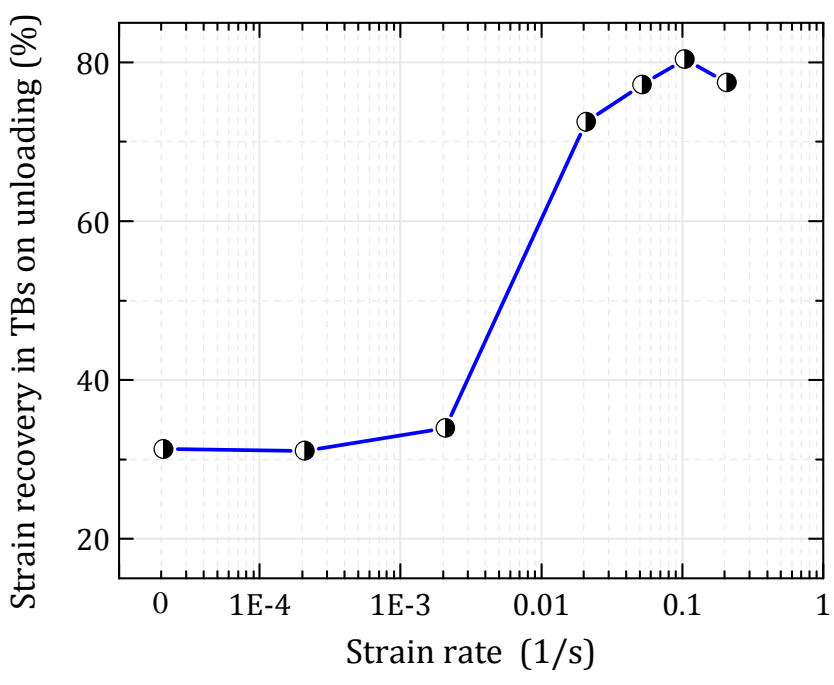

Figure 15. Effect of strain rate on strain recovery in TBs (as \% of maximum applied strain) Tests $8-14$.

9 The strain recovery within the coalesced TBs may not be always homogeneous, see Figure 14. In Test 11, upon 10 unloading, the strain recovery within the upper TB is different at top and bottom fronts of the band (see Figure 14(b)).

11 The bottom front of the TB, shown with a dotted rectangle in Figure 14(b), is found to retain approximately $5 \%$ strain 12 while the top front of the same band retained only $2 \%$. The is due to non-uniform heat conduction within the specimen 13 which leads to non-uniform strain recovery.

\section{4. Conclusions}

15 A series of experimental tests were conducted to study the effect of strain localisation effect in 2 mm diameter NiTiNb 16 SMA wires under different loading protocols and strain rates. All the tests were conducted at room temperature, in either 17 strain-control or displacement-control. Full-field strain contours of the specimens were obtained using the DIC. The 18 effect of strain rate was investigated within the quasi-static range of $3.3 \times 10^{-5} / \mathrm{s}$ to $3.3 \times 10^{-2} / \mathrm{s}$ in the strain-controlled tests 19 and $2 \times 10^{-5} / \mathrm{s}$ to $2 \times 10^{-1} / \mathrm{s}$ in the displacement-controlled tests. 
1 This study has demonstrated that the SMA wires exhibit significant strain localisation behaviour due to the formation

2 of martensite transformation bands (TB). The following conclusions can further be drawn from this study:

1. Stress-induced martensite phase transformation in the NiTiNb wires progressed through the nucleation and broadening of TBs. The nucleation of each TB instantly results in local strain of $\sim 8 \%$.

2. The strain within the transformation bands is limited to about $8 \%$ until the propagation of all the TBs within the specimen is completed. Once the entire specimen is fully transformed, strain begins to increase almost, but not perfectly, uniformly throughout the specimen.

3. The nucleation of the transformation band at higher strain rates is accompanied by a sudden generation of relatively large strains, leading to large and sudden stress-drops. The drop in the stress during the nucleation of TB increases with an increase of strain rate.

4. In the displacement-controlled loading, due to the constrained movement of the crosshead, the exact drop in the stress during the nucleation of TB may not be fully captured if the strain in the TBs is produced at a rate higher than the rate of crosshead movement.

5. Only a slight increase in the yield stress is observed as the strain rate increases within the quasi-static range. However, the slope of the stress plateau increases considerably as the strain rate increases.

6. The strain recovery in NiTiNb SMAs increases with the increase of strain rate. A marked change in strain recovery can be observed for strain rates higher than $3.3 \times 10^{-4} / \mathrm{s}$.

\section{Acknowledgements}

Financial support received from Queen's University Belfast in the form of a $\mathrm{PhD}$ studentship for the first author is gratefully acknowledged.

\section{References}

[1] Otsuka, K. and Wayman, C.M. eds., 1999. Shape memory materials. Cambridge university press.

[2] Kumar, P.K. and Lagoudas, D.C., 2008. Introduction to shape memory alloys. In Shape memory alloys (pp. 1-51). Springer, Boston, MA.

[3] Saburi, T., 1998. Ti-Ni shape memory alloys. Shape memory materials, pp.49-96.

[4] Van Humbeeck, J., 1999. Non-medical applications of shape memory alloys. Materials Science and Engineering: A, 273, pp.134-148. 
[5] Song, G., Ma, N. and Li, H.N., 2006. Applications of shape memory alloys in civil structures. Engineering structures, 28(9), pp.1266-1274.

[6] Lecce, L. ed., 2014. Shape memory alloy engineering: for aerospace, structural and biomedical applications. Elsevier.

[7] Zhao, L.C., Duerig, T.W., Justi, S., Melton, K.N., Proft, J.L., Yu, W. and Wayman, C.M., 1990. The study of niobium-rich precipitates in a Ni Ti Nb shape memory alloy. Scripta Metallurgica et Materialia, 24(2), pp.221-225.

[8] Bao, Z.Z., Shun, G.U.O., Fu, X.I.A.O. and Zhao, X.Q., 2011. Development of NiTiNb in-situ composite with high damping capacity and high yield strength. Progress in Natural Science: Materials International, 21(4), pp.293-300.

[9] Suhail, R., 2018. Heat-activated Prestressing of SMA Wires for Seismic Retrofitting of RC Beam-Column Joints. Ph.D. thesis. Queen's University Belfast.

[10] Choi, E., Cho, S.C., Hu, J.W., Park, T. and Chung, Y.S., 2010. Recovery and residual stress of SMA wires and applications for concrete structures. Smart Materials and Structures, 19(9), p.094013.

[11] Dolce, M. and Cardone, D., 2001. Mechanical behaviour of shape memory alloys for seismic applications 2. Austenite NiTi wires subjected to tension. International journal of mechanical sciences, 43(11), pp.2657-2677.

[12] Dommer, K. and Andrawes, B., 2012. Thermomechanical characterization of NiTiNb shape memory alloy for concrete active confinement applications. Journal of Materials in Civil Engineering, 24(10), pp.1274-1282.

[13] Suhail, R., Amato, G., Chen, J.F. and McCrum, D., 2016. Heat Activated Prestressing of Ni48. 46Ti36. 03Nb15. 42 Shape Memory Alloy for Active Confinement of Concrete Sections. Proceedings of the Civil Engineering Research in Ireland, Galway, Ireland, pp.29-30.

[14] Menna, C., Auricchio, F. and Asprone, D., 2015. Applications of shape memory alloys in structural engineering. In Shape Memory Alloy Engineering (pp. 369-403). Butterworth-Heinemann.

[15] Dolce, M., Cardone, D. and Ponzo, F.C., 2007. Shaking - table tests on reinforced concrete frames with different isolation systems. Earthquake Engineering \& Structural Dynamics, 36(5), pp.573-596.

[16] Czaderski, C., Hahnebach, B. and Motavalli, M., 2006. RC beam with variable stiffness and strength. Construction and Building Materials, 20(9), pp.824-833.

[17] Iadicola, M.A. and Shaw, J.A., 2004. Rate and thermal sensitivities of unstable transformation behavior in a shape memory alloy. International Journal of Plasticity, 20(4-5), pp.577-605.

[18] Liu, Y., Liu, Y. and Van Humbeeck, J., 1998. Luders-like deformation associated with martensite reorientation in NiTi. Scripta materialia, 39(8).

[19] Zhang, X., Feng, P., He, Y., Yu, T. and Sun, Q., 2010. Experimental study on rate dependence of macroscopic domain and stress hysteresis in NiTi shape memory alloy strips. International Journal of Mechanical Sciences, 52(12), pp.1660-1670.

[20] Bhattacharya, K., 2003. Microstructure of martensite: why it forms and how it gives rise to the shape-memory effect (Vol. 2). Oxford University Press.

[21] Churchill, C.B., Shaw, J.A. and Iadicola, M.A., 2009. Tips and tricks for characterizing shape memory alloy wire: Part 2fundamental isothermal responses. Experimental Techniques, 33(1,) pp.51-62.

[22] Leo, P.H., Shield, T.W. and Bruno, O.P., 1993. Transient heat transfer effects on the pseudoelastic behavior of shape-memory wires. Acta Metallurgica et Materialia, 41(8), pp.2477-2485.

[23] Shaw, J.A. and Kyriakides, S., 1995. Thermomechanical aspects of NiTi. Journal of the Mechanics and Physics of Solids, 43(8), pp.1243-1281.

[24] Hallai, J.F. and Kyriakides, S., 2013. Underlying material response for Lüders-like instabilities. International Journal of Plasticity, 47, pp.1-12.

[25] Brinson, L.C., Schmidt, I. and Lammering, R., 2004. Stress-induced transformation behavior of a polycrystalline NiTi shape memory alloy: micro and macromechanical investigations via in situ optical microscopy. Journal of the Mechanics and Physics of Solids, 52(7), pp.1549-1571.

[26] Daly, S., Ravichandran, G. and Bhattacharya, K., 2007. Stress-induced martensitic phase transformation in thin sheets of Nitinol. Acta Materialia, 55(10), pp.3593-3600. 
[27] Adharapurapu, R.R., Jiang, F., Vecchio, K.S. and Gray III, G.T., 2006. Response of NiTi shape memory alloy at high strain rate: A systematic investigation of temperature effects on tension-compression asymmetry. Acta materialia, 54(17), pp.46094620.

[28] Nemat-Nasser, S. and Guo, W.G., 2006. Superelastic and cyclic response of NiTi SMA at various strain rates and temperatures. Mechanics of materials, 38(5-6), pp.463-474.

[29] Shin, M. and Andrawes, B., 2009. Uniaxial compression behavior of actively confined concrete using shape memory alloys. In Structures Congress 2009: Don't Mess with Structural Engineers: Expanding Our Role (pp. 1-8).

[30] Andrawes, Bassem, Moochul Shin, and Nicholas Wierschem. "Active confinement of reinforced concrete bridge columns using shape memory alloys." Journal of Bridge Engineering 15, no. 1 (2009): 81-89.

[31] Bisby, L.A., Chen, J.F., Li, S.Q., Stratford, T.J., Cueva, N. and Crossling, K., 2011. Strengthening fire-damaged concrete by confinement with fibre-reinforced polymer wraps. Engineering Structures, 33(12), pp.3381-3391

[32] GOM Correlate, “GOM Correlate.” GOM GmbH Schmitzstraße 238122 Braunschweig Germany, 2017.

[33] Sutton, M.A., Orteu, J.J. and Schreier, H., 2009. Image correlation for shape, motion and deformation measurements: basic concepts, theory and applications. Springer Science \& Business Media.

[34] Zhang, C.S., Wang, Y.Q., Chai, W. and Zhao, L.C., 1991. The study of constitutional phases in a Ni47Ti44Nb9 shape memory alloy. Materials Chemistry and Physics, 28(1), pp.43-50.

[35] Standard A.S.T.M "E8/E8M," "Standard Test Methods for Tension Testing of Metallic Materials.” ASTM International, pp. 1-27, 2009.

[36] Standard A.S.T.M "F 2516-07," "Standard Test Method for Tension Testing of Nickel-Titanium Superelastic Materials." ASTM International, pp. 1-7, 2007.

[37] Churchill, C.B., Shaw, J.A. and Iadicola, M.A., 2009. Tips and tricks for characterizing shape memory alloy wire: part 3localization and propagation phenomena. Experimental Techniques, 33(5). pp 70-78.

[38] Pieczyska, E., 2010. Activity of stress-induced martensite transformation in TiNi shape memory alloy studied by infrared technique. Journal of Modern Optics, 57(18), pp.1700-1707.

[39] Corona, E., Shaw, J.A. and Iadicola, M.A., 2002. Buckling of steel bars with Lüders bands. International journal of solids and structures, 39(13-14), pp.3313-3336. 